\title{
Direitos internacionais e a participação ativa de crianças e adolescentes na sua efetivação: o caso de Malala Yousafzai
}

International rights and the active participation of children and adolescents in their effectiveness: the case of Malala Yousafzai

Gláucia Borges ${ }^{1}$ (D) e Ismael Francisco de Souza ${ }^{2}$

${ }^{1}$ Escola Superior de Criciúma (ESUCRI), mestre em Direito pela Universidade do Extremo Sul Catarinense (UNESC), email: glauciaborges@icloud.com

${ }^{2}$ Universidade do Extremo Sul Catarinense (UNESC), doutor em Direito pela Universidade Santa Cruz do Sul (UNISC), email: ismael@unesc.net

\section{RESUMO}

O presente escrito trata sobre a atuação de crianças e adolescentes como grupo social nas Relações Internacionais, levando-se em consideração os tratados internacionais já firmados. Através do exemplo da militante paquistanesa Malala Yousafzai, se pretende demonstrar a possibilidade e a importância da participação das crianças e dos adolescentes nos espaços de criação dos direitos. Para isso, foi feita uma construção dos mais importantes regulamentos firmados no campo internacional, partindo da Declaração Universal dos Direitos Humanos até a Convenção dos Direitos da Criança de 1989. Depois, foi relatado o caso Malala Yousafzai e, por fim, feita discussão sobre a importância da presença de crianças e adolescentes na efetivação dos direitos internacionais. O método utilizado foi o dedutivo e, de procedimento, os métodos histórico e monográfico, utilizando-se da técnica de pesquisa bibliográfica.

Palavras-chave: Crianças e adolescentes. Direitos Humanos. Participação.

\begin{abstract}
This paper deals with the role of children and adolescents as a social group in International Relations, taking into account the international treaties already signed. Through the example of Pakistani militant Malala Yousafzai, it is intended to demonstrate the possibility and importance of the participation of children and adolescents in the creation of rights. In order to achieve this, the most important regulations established in the international field were drawn up, starting with the Universal Declaration of Human Rights up to the Convention on the Rights of the Child of 1989. The Malala Yousafzai case was then reported and, finally, a discussion on the importance of the presence of children and adolescents in the realization of international rights. The method used was the deductive and, of procedure, the historical and monographic methods, using the technique of bibliographic research.
\end{abstract}

Keywords: Children and adolescentes. Human rights. Participation. 


\section{INTRODUÇÃO}

Cada vez mais a discussão sobre a efetividade dos direitos das crianças e dos adolescentes se faz importante, vez que, apesar de termos diversas regulamentações no âmbito internacional e nacional firmadas, os direitos deste grupo social ainda têm sido amplamente violados.

A infância nem sempre foi objeto de estudo e a categoria de sujeito de direitos, na forma como hoje é vista, é recente. Por isso, se instalou uma cultura de que crianças e adolescentes não possuem as devidas percepções sobre seus direitos, sendo física e mentalmente imaturas para atuarem em favor de seus direitos, o que dificulta o acesso a sua participação, situação que o “adultocentrismo" ainda vigora.

É pública e notória a importância que o grupo social atingido pelas normas tenha nos organismos responsáveis a sua devida representação, contudo, no que tange as crianças e aos adolescentes, os principais atores sociais destes direitos, são excluídos.

Focando especialmente no campo internacional, encontramos uma série de tratados, conquistados por uma histórica evolução, onde crianças e adolescentes são, na letra da lei, revestidos de direitos como de expressão, participação e desenvolvimento, mas, na prática, percebemos que não têm se efetivado e, por isso, o presente trabalho pretende demonstrar a importância e o cabimento desta atuação.

Para atender a esse propósito, será inicialmente levantada a questão das normativas internacionais, primeiro brevemente quanto aos Direitos Humanos, vez que a Declaração de 1948 é, de maneira geral a todos os seres humanos, a positivação mais importante na busca de uma vida digna e, depois, ainda no campo internacional, os tratados e convenções que marcaram as principais conquistas das crianças e adolescentes.

No capítulo seguinte, traremos o exemplo vivido por Malala Yousafzai, na tentativa de demonstrar a força que crianças e adolescentes podem ter, bem como que, se devidamente instruídas, como foi o caso da paquistanesa, podem estes entender seu papel na luta, na garantia e na efetivação dos seus direitos. Por fim, no último capítulo, buscaremos demonstrar a significação da participação das crianças e dos adolescentes, especialmente no campo internacional.

O método utilizado foi o dedutivo e, de procedimento, os métodos histórico e monográfico, utilizando-se da técnica de pesquisa bibliográfica.

Ciências Sociais Aplicadas em Revista, v. 20, n. 38, p. 278-290, semestral, janeiro-junho, 2020. 


\section{OS DIREITOS HUMANOS E OS DIREITOS DAS CRIANÇAS E DOS ADOLESCENTES NAS RELAÇÕES INTERNACIONAIS}

Os Direitos Humanos são processos das lutas dos seres humanos para obtenção de bens materiais e imateriais para que a vida seja digna de ser vivida, sendo que naturalmente os temos, exclusivamente por nascermos seres humanos, independentemente de qualquer condição, não se confundindo com os direitos positivados, seja em nível nacional ou internacional (FLORES, p. 2829).

Estes direitos são, portanto, algo que todos deveríamos ter para alcançarmos uma vida digna. Contudo, se estes direitos estivessem na prática garantidos, não haveria motivo para luta ou até para positivá-los internacionalmente (FLORES, 2009, p. 37).

Nesse sentido, em 10 de dezembro de 1948, na Assembleia Geral das Nações Unidas, foi proclamada a Declaração Universal dos Direitos Humanos (inicialmente dita como Direitos do Homem), sendo uma orientação universal de uma série de direitos básicos para que todos alcancem a citada vida digna.

Apesar da adoção da Declaração Universal, é importante entendermos que os Direitos Humanos não se reduzem a um único momento histórico ou um único formalismo jurídico-legal (RÚBIO, 2010, p. 41).

A Declaração Universal foi um marco na história da humanidade, que havia acabado de passar por duas guerras mundiais, trazendo uma reaproximação com os valores morais. Há de se concordar que houve grande esforço da comunidade internacional para que houvesse uma gama de direitos que alcançassem a todos e "desde 1948 até nossos dias, assistimos cotidianamente a esse trabalho levado a cabo pela comunidade internacional para que os seres humanos possam controlar seus destinos" (FLORES, 2009, p. 23).

Segundo Wolkmer (2003, p. 11) a "história expressa a complexa manifestação da experiência humana interagida no bojo de fatos, acontecimentos e instituições”, e é justamente o caráter mutável, imperfeito e relativo da experiência humana que nos permite proceder múltiplas interpretações da mesma e modifica-la, formulando histórias diferentes, que nos faz recriar a atual realidade.

Quando adentramos no campo das crianças e dos adolescentes, sabendo que é recente a construção social dos Direitos Humanos, também o é o reconhecimento da categoria criança e adolescente como sujeitos de direitos e, "a forma como eram pouco consideradas expressa parte do 
funcionamento da sociedade, em seus diversos processos" (FUZIWARA, 2013, p. 527), pois a humanidade somente passou a reconhecê-los efetivamente como categoria de direitos há menos de dois séculos, sendo vitimados pela recusa do reconhecimento das suas condições peculiares de pessoas em desenvolvimento (FUZIWARA, 2013, p. 528-529).

Nesse sentido:

[...] el establecimiento de derechos específicos para los niños no fue tomado en consideración hasta que surgiera un mundo infantil separado del de los adultos y que requería normas especiales. Desde este punto de vista, los Derechos del Niño no pueden considerarse como una mera extensión de los Derechos Humanos hacia los niños, sino una forma de derechos especiales que sirven para la conservación y la cultivación de este mundo infantil (LIEBEL, 2009, p. 24).

Entre outros grupos de sociais, as crianças e os adolescentes sofreram e ainda sofrem desigualdades, vez que lhes foi negada a mesma identidade de pessoa ou sua capacidade de cidadania (RÚBIO, 2010, p. 30), o que impossibilita a luta pela vida digna que os Direitos Humanos tentam garantir.

Apesar de se considerar os direitos das crianças e dos adolescentes como Direitos Humanos, suas histórias são notavelmente diferentes. Em geral, a história dos Direitos Humanos começou em decorrência da necessidade de direitos de liberdade aos cidadãos. Em contrapartida, os direitos das crianças e dos adolescentes se iniciaram pela necessidade de proteção (LIEBEL, 2009, p. 24).

Foi somente em 1919 que a Liga das Nações instituiu o Comitê de Proteção à infância, que foi considerado o primeiro órgão governamental supranacional direcionado às crianças e adolescentes, após a calamidade da Primeira Guerra Mundial (BASTOS, 2012, p. 45) e esse reconhecimento jurídico internacional dos direitos das crianças muito se deve a inglesa fundadora do Save the Children, Eglantyne Jebb (VILLASENOR; SAUCEDO; SILVA, 2017, p. 172). Podemos dizer que, a partir daqui (1919), foi iniciada uma conscientização internacional da situação das crianças no que tange às suas necessidades específicas.

Em 1924, na Declaração de Genebra, representando o primeiro documento internacional sobre os direitos da criança, a Liga das Nações adotou a Convenção dos Direitos da Criança, elaborada por Eglantyne Jebb, afirmando que as crianças têm direito ao desenvolvimento material, moral e espiritual; a receber ajuda especial quando estão com fome, doentes, inválidos ou órfãos; que sejam prioritariamente socorridos em situações graves; ainda, a estarem protegidos contra qualquer exploração econômica; e, receber uma educação que lhes dê o sentimento de responsabilidade social (VILLASEÑOR; SAUCEDO; SILVA, 2017, p. 172). 
No ano de 1946, a ONU criou o Fundo Internacional de Ajuda Emergencial à Infância Necessitada - UNICEF, em decorrência da Segunda Guerra Mundial, objetivando auxiliar as crianças dos países devastados pela Segunda Guerra Mundial (BASTOS, 2012, p. 46).

Nesse caminho, em 1959, foi proclamada pelas Nações Unidas a Declaração Universal dos Direitos da Criança, reafirmando que as crianças possuem direitos especiais para a proteção do seu desenvolvimento físico, mental e social, lhes dando o direito a igualdade, independente de raça, gênero, religião ou nacionalidade (ONU, 1959). Nesta, “a criança passa a ser ineditamente considerada prioridade absoluta e sujeito de direitos em sentido amplo”, situação que a Doutrina da Proteção Integral passa timidamente a surgir (BASTOS, 2012, 46-47).

Em 1969, os Estados americanos convieram quanto a Convenção Americana sobre Direitos Humanos, chamado de Pacto de San José da Costa Rica, na Conferência Especializada Interamericana sobre Direitos Humanos, estabelecendo em seu artigo 19, a seção dos Direitos da Criança, dando melhores contornos ao conceito de Proteção Integral, onde: "Toda criança tem direito às medidas de proteção que a sua condição de menor $^{1}$ requer por parte da sua família, da sociedade e do Estado" (OEA, 1969).

No entanto, foi em 1989 que a Organização das Nações Unidas aprovou a Convenção sobre os Direitos da Criança, pautada no conceito do interesse superior da criança, que engloba todo o elenco dos direitos humanos, reconhecendo e garantindo diversos direitos a estas (ONU, 1989).

A Convenção é um tratado integral de Direitos Humanos de todas as crianças e adolescentes do mundo e tem sido o tratado jurídico internacional com o maior número de ratificações pelos países (BOZZI, 2011, p. 109). É o instrumento internacional mais importante no que tange aos direitos das crianças e dos adolescentes e:

[...] se verá cómo a finales del siglo XX, con la entrada de la Convención sobre los Derechos del Niño de Naciones Unidas, la infancia (a modo de concepto), inicia un proceso de importancia trascendente como una etapa con sus propias características y necesidades y se empieza a reconocer igualmente al niño como persona con derechos a la identidad, a la dignidad y a la libertad, entre otros derechos (GALICIA, 2016, p. 19).

Foi a partir da Convenção de 1989 que se consolidou, efetivamente, o Paradigma da Proteção Integral (BOZZI, 2011, p. 110), reconhecendo definitivamente as crianças e os adolescentes como sujeitos de direitos, em razão de seu peculiar estado de desenvolvimento.

\footnotetext{
${ }^{1}$ A expressão “menor” não é mais utilizada após o advento efetivo do Paradigma da Proteção Integral, por estigmatizar as crianças e adolescentes.
}

Ciências Sociais Aplicadas em Revista, v. 20, n. 38, p. 278-290, semestral, janeiro-junho, 2020. 
Importante destacar que a Convenção considera criança todo ser humano com menos de 18 anos de idade (ONU, 1989) e, por isso, não há menção da expressão "adolescente" no título ou em todo o tratado.

Os paradigmas são modelos culturais, decorrentes da experiência humana na história, sistematizados através da racionalização, com concepções, significados e valores específicos (WOLKMER, 2015, p. 24), nesse viés, o Paradigma da Proteção Integral trouxe uma nova visão em todo o mundo quanto ao tratamento que deve ser dado a todas as crianças e aos adolescentes.

Galicia (2019, p. 20) explica que, quando repetidamente falamos sobre o reconhecimento das crianças e dos adolescentes como sujeitos de direitos, quando anteriormente mostramos que já haviam normas especialmente a elas destinadas, é porque, até então, as crianças e os adolescentes eram concebidas como sujeitos com necessidade de proteção e ai está a diferença, pois este era seu direito único, que estava acima da possibilidade de exercer outros direitos.

Entender que os “[...] Derechos del Niño son derechos de los niños, es decir que son derechos que ellos mismos pueden ejercer (o la garantía de que nada puede ocurrir contra su voluntad)" (LIEBEL, 2009, p. 25), o que anteriormente não ocorria.

Nesse sentido, a partir do Paradigma da Proteção Integral, as crianças e os adolescentes possuem valor em si mesmos e não por aquilo que irão se tornar (adultos), não podendo ser excluídos das decisões que irão afetar as suas próprias vidas (BOZZI, 2009, p. 110).

Em decorrência então do status que as crianças e os adolescentes possuem no período vigente, sua atuação enquanto grupo social deve ser considerado em todas as suas relações, seja ela nacional ou internacional, pública ou privada, evidenciando a essencialidade de sua participação para garantia de todos os direitos já reconhecidos, bem como na discussão daqueles que ainda se fazem necessários.

Apesar da aqui demonstrada evolução histórica dos direitos das crianças e dos adolescentes, esta classe social ainda muito é impedida de acessar os espaços os quais os direitos são formulados ou de serem vozes ativas na sua garantia, muito porque os adultos entendem que estes não possuem capacidade de fazê-lo. Por isso, no próximo tópico, demonstraremos um caso concreto que desmistifica esta cultura.

Ciências Sociais Aplicadas em Revista, v. 20, n. 38, p. 278-290, semestral, janeiro-junho, 2020. 


\section{O CASO MALALA YOUSAFZAI NA LUTA PELOS DIREITOS}

Para muitos, a opinião e a participação das crianças e dos adolescentes no resguardo dos seus direitos não são importantes ou não são necessárias, pois, em tese, estas não possuem as percepções da vida como cidadãos, sob a ótica do critério cronológico, onde estariam devidamente protegidas pelos adultos que as representam.

Por isso, ainda não é uma realidade o exercício pleno dos direitos das crianças e dos adolescentes, necessitando de uma urgente reflexão nesse aspecto, pois ainda existem muitos assuntos pendentes para que a situação destes seja melhorada. É de suma importância impulsionar a participação deste grupo social, para que sejam, eles mesmos, os atores sociais que impulsionam uma nova cultura de cidadania (BOZZI, 2009, p. 105-106) e, assim se reconheçam, como cidadãos.

Nessa percepção de participação, seja ela nacional ou internacional, trazemos o exemplo de Malala Yousafzai, que desfaz a percepção de incapacidade das crianças e dos adolescentes.

Malala Yousafzai nasceu em 1997, no Paquistão. Aos 11 anos de idade, Malala defendia em seu blog na internet seu direito à educação, criticando a oposição do grupo Talibã ao ensino feminino (YOUSAFZAI, 2013, p. 164-166), vez que este era garantido pela Convenção das Nações Unidas sobre os Direitos da Criança de 1989.

A paquistanesa sempre foi muito incentivada por seu genitor, que também lutava para que todos e todas em seu país tivessem o direito e o acesso à educação, bem como demonstrava à Malala a importância da educação e de defender seus direitos (YOUSAFZAI, 2013, p. 35-66).

Apesar de sua idade desde que iniciou sua luta (menos de 18 anos), a prova de que Malala, enquanto criança e/ou adolescente possuía força na sua luta, o grupo Talibã cometeu um atentado contra a sua vida, em 2012, quando esta possuía apenas 15 anos de idade (YOUSAFZAI, 2013, p. 17), porém, apesar de ser alvejada na cabeça, a paquistanesa sobreviveu e, após se recuperar, tornou a sua luta.

No ano do atentado, por Gordon Brown (ex-Primeiro Ministro do Reino Unido), foi lançada na ONU uma petição em nome de Malala, com o slogan “I am Malala” ("Eu sou Malala”), exigindo que todas as crianças do mundo estivessem inscritas em escolas até ao fim de 2015, o que impulsionou a retificação da primeira lei de direito à educação no Paquistão (MARTUSCELLI, 2013, p. 101).

O slogan "Eu sou Malala" é uma resposta direta a pergunta feita pelo integrante do grupo Talibã no momento do atentado, vez que Malala estava se dirigindo à escola com outras colegas,

Ciências Sociais Aplicadas em Revista, v. 20, n. 38, p. 278-290, semestral, janeiro-junho, 2020. 
situação que, o atirador, ao abordar o transporte, questionou quem era a Malala e, ao ser apontada, foi alvejada (YOUSAFZAI, 2013, p. 17).

Em 12 de julho de 2013, Malala discursou na sede da ONU, pedindo acesso universal à educação, deixando, entre outras, a marca de sua frase "uma criança, um professor, um livro e uma caneta podem mudar o mundo. A educação é a única solução”. Apesar de ainda ameaçada pelo grupo Talibã, o que a impede de voltar a morar no Paquistão, Malala prossegue lutando para que todas as crianças e adolescentes tenham a garantia da educação, especialmente as mulheres, pois estas são, segundo a militante, as que mais sofrem.

Juntamente com seu pai, Ziauddin Yousafzai, fundou o "Malala Fund”, uma instituição de caridade dedicada a dar a todas as mulheres a oportunidade de estudo. Em reconhecimento a este trabalho, a militante recebeu o Prêmio Nobel da Paz em dezembro de 2014, aos 17 anos de idade, se tornando a mais jovem vencedora do Nobel (MALALA FUND, 2018).

Malala Yousafzai é um exemplo de que as crianças podem atuar ativamente na política e
em suas sociedades e que suas ações têm repercussões na vida de milhares de pessoas. O
avanço da tecnologia da comunicação aparece nesse caso como uma maneira de
participação das crianças na esfera pública. O caso da paquistanesa mostra como na
realidade uma criança pode impactar um país inteiro e sensibilizar o mundo. Assim, faz-
se necessário estudar a ação das crianças como grupo social nas Relações Internacionais e
entender porque a disciplina mantém em silêncio essa atuação (MARTUSCELLI, 2013,
p. 101).

Muitos poderiam aqui ser dados como exemplos, não só na esfera individual, mas também nas lutas coletivas (Primavera Árabe, Movimento Occupy Wall Street, manifestações no Brasil em junho 2013...), no entanto, o caso aqui trazido de Malala Yousafzai mostra nitidamente a força e a potência que crianças e adolescentes possuem tanto na percepção dos seus direitos (se a elas for ensinado), quanto na execução e luta pelos mesmos.

\section{A IMPORTÂNCIA DA PARTICIPAÇÃO DAS CRIANÇAS E DOS ADOLESCENTES NA EFETIVAÇÃO DE SEUS DIREITOS INTERNACIONAIS}

Analisando o exemplo dado por Malala Yousafzai, vemos a essencialidade da participação de crianças e adolescentes ativamente no que diz respeito a garantia e a efetivação de seus direitos. Mesmo assim, as aqui focadas Relações Internacionais não as reconhecem como agentes sociais de participação em decorrência da dita imaturidade física e intelectual.

Ciências Sociais Aplicadas em Revista, v. 20, n. 38, p. 278-290, semestral, janeiro-junho, 2020. 
Essa cultura da não participação instaurada, uma vez que por muitos anos crianças e adolescentes sequer foram vistos como sujeitos de direitos, como no primeiro tópico fora discutido, continua associando estes somente à esfera privada e doméstica, situação que não participam do âmbito público onde são tomadas as decisões (MARTUSCELLI, 2013, p. 101).

Grande parte desta problemática está ligada ao "adultocentrismo", que rege as relações entre os adultos e as crianças, em uma verdadeira relação assimétrica de poder, onde os adultos, segundo Villaseñor, Saucedo e Silva:

[...] ven y consideran a la niñez como seres inacabados, incompletos, imperfectos, despendientes, invisibles, inmaduros, irracionales; y por el contrario, los adultos se consideran acabados, completos, perfectos, independientes, visibles, maduros y racionales. En otras palavras, la infância es una categoría que há estado situada en una relación de subordinación y dependencia para con los adultos, es decir, de opressión (2017, p. 174-175).

A palavra infância decorre de enfant, que significa "não falante", indicaria a fase até os 07 anos de idade, quando a linguagem ainda é frágil, decorrente da condição biológica (FUZIWARA, 2013, p. 529), contudo, estigma a posição de que qualquer criança ou adolescente não podem ser ouvidos ou ter voz enquanto adultos não se tornarem.

Pelo fato, também, de não poderem se auto representar, muitas vezes não conhecem ou sequer são apresentados aos seus direitos, o que pode influenciar na formação de adultos que se distanciam da democracia e da vida político-social.

O artigo 12 da Convenção sobre os Direitos da Criança assim confirma o direito de expressão:

1. Os Estados Partes assegurarão à criança que estiver capacitada a formular seus próprios juízos o direito de expressar suas opiniões livremente sobre todos os assuntos relacionados com a criança, levando-se devidamente em consideração essas opiniões, em função da idade e maturidade da criança. [...] (ONU, 1959)

Além da especificidade do artigo supracitado, a Convenção reconhece às crianças diversos direitos, como o de participação e desenvolvimento, onde estão incluídos os direitos civis e políticos, havendo reconhecimento da comunidade internacional e dos Estados membros (MARTUSCELLI, 2013, p. 113).

Conforme disposto nos tratados Internacionais e, em especial na Convenção de 1989, o exercício dos direitos dos infantoadolescentes independe de qualquer condição, seja ela legal ou 
social, e isto pode ser rompido se houver contrários entendimentos (GALICIA, 2016, p. 18), o que representaria um retrocesso.

É uma falha dos organismos internacionais não valorizar a capacidade das crianças e dos adolescentes e de não considerar a presença destas nos assuntos que tanto preocupam a humanidade, como "aquisição de direitos, igualdade, desenvolvimento, pobreza e segurança" (MARTUSCELLI, 2013, p. 113), pois as afetam diretamente.

Quando discutimos assuntos referentes a violação de direitos ou a necessidade de criação dos mesmos para algum grupo social, convém serem ouvidos aqueles que passam por aquela exclusão, pela não garantia dos direitos, o preconceito e qualquer outro tipo de violação ou até mesmo para quem o direito e/ou o dever se destinam, para se entender a real necessidade daqueles que serão diretamente afetados pelas decisões do Estado e serem encontradas as melhores formas de garantia e isto deveria se aplicar a qualquer grupo, como é o exemplo que acontece com as mulheres, as pessoas com deficiência, os negros, os trabalhadores etc. Não obstante, quando a discussão se dá com relação aos direitos do grupo social crianças e adolescentes, estes não se fazem presentes.

Se, para enfrentarmos a questão da violação de Direitos Humanos das crianças e dos adolescentes necessitamos de articulações da nossa atual sociedade e das ideologias dos que elaboram as políticas públicas (FUZIWARA, 2013, p. 540), como podemos excluí-los, quando estas são as maiores interessadas na efetivação de seus direitos? Se os adultos as representassem tão bem, não haveria tantos direitos deste grupo ainda sendo mundialmente violados.

\begin{abstract}
Reconhecer a importância do estudo das crianças nas Relações Internacionais pode trazer novos temas para a agenda de pesquisa, tais como: crianças soldado, tráfico e adoção internacional de crianças, trabalho infantil, exploração sexual e comercial de menores, crianças refugiadas, menores migrantes desacompanhados e separados, a relação entre direitos da criança e estudos de desenvolvimento, a questão das gerações futuras. Além disso, pode mudar a concepção do estudo de temas tradicionais, como segurança, desenvolvimento, conflitos armados, entre outros. Por fim, é provável que muitas crianças no mundo não tenham consciência do que é ser um ator internacional ou não ambicionem tal meta. No entanto, nunca houve uma consulta a esse grupo sobre sua opinião, sobre se elas querem ou não ser agentes das Relações Internacionais (MARTUSCELLI, 2013, p. 114).
\end{abstract}

Na realidade, excluir as crianças e os adolescentes das Relações Internacionais corresponde como uma forma de desproteção, pois as deixa sem ter para quem recorrer quando o âmbito nacional viola seus direitos (MARTUSCELLI, 2013, p. 114-115). 
Cuando los ninõs perciben que sus opiniones son tomadas seriamente en consideración, asumen una postura ante la vida que difere en mucho de uma posición subalterna y resignada. Su autoestima es promovida $\mathrm{y}$, consecuentemente, el niño desarolla el sentimento de que es importante. Se reconocen como seres humanos iguales a los adultos y desarrollan un respeto mayor por sus semejantes (BOZZI, 2009, p. 114)

Estimular a participação de crianças e adolescentes na luta pelos seus direitos não é priválos da infância e querer torná-los "pequenos" adultos, mas sim, demonstrar que possuem importância na nossa sociedade e ter a chance de melhorá-la.

A participação infantil é uma oportunidade para o desenvolvimento de sua autonomia, autoestima, independência e habilidades sociais (BOZZI, 2009, p. 114), sendo necessário a criação de espaços que permitam as crianças, adolescentes e jovens se expressarem, trabalharem as consequências da vida cotidiana e visualizarem alternativas para responder as circunstâncias diárias, ou seja, a criação de espaços que permitam esta participação (BOZZI, 2009, p. 113), que hoje estão preparados tão somente para os adultos.

Além da necessidade da criação de espaços, para o exercício da representação social feito pelas próprias crianças e adolescentes, os adultos devem redefinir os conceitos que possuem sobre a infância, onde, “devem deixar de olhar para as crianças apenas como objetos de tutela, deixar de considerar que as crianças são adultas em miniatura, começar a visualizar as crianças como titulares de seus direitos, que devem e são capazes de exercê-los" (GALICIA, 2016, p. 65-67) (tradução nossa).

Nenhum paradigma está livre de crises estruturais, mas, enquanto for capaz de dar resolução aos problemas, deverá continuar (WOLKMER, 2015, p. 77). O Paradigma da Proteção Integral, nesse sentido, traz todas as modalidades necessárias de garantia às crianças e aos adolescentes, o que lhes dá suporte para efetiva participação no que diz respeito aos seus direitos.

Por isso, entendemos que as crianças e os adolescentes devem ter, dos organismos internacionais, a abertura para atuação e, do Estado, da sociedade e da família o incentivo na participação da vida político-social, para que sejam, efetivamente, sujeitos de direitos, fazendo cumprir o Paradigma da Proteção Integral.

\section{CONSIDERAÇÕES FINAIS}

O marco jurídico internacional do Paradigma da Proteção Integral, devidamente firmado na Convenção dos Direitos da Criança de 1989 e reconhecido pelos Estados signatários, protege e 
garante os direitos dos quais as crianças e adolescentes são titulares, os transformando em verdadeiros sujeitos de direitos e, desde o seu advento, muito se tem buscado para que estes sejam devidamente cumpridos na prática, indo além de uma teoria.

A discussão sobre a defesa e a garantia dos direitos das crianças e dos adolescentes é de suma importância para sua efetivação, onde entendemos que, para isso, se faz necessária a verdadeira construção da possibilidade de acesso nos órgãos responsáveis, como atores sociais, não havendo necessidade de serem criadas outras normativas para o pleno exercício, vez que há muito já foi declarado nos tratados internacionais que crianças e adolescentes possuem capacidade para exercer seus direitos, logo, argumentos contrários vão de encontro com a legislação internacional vigente.

Portanto, é importante estabelecermos a conexão do paradigma da Proteção Integral com a teoria da representação social feita pelas próprias crianças e adolescentes, porquê os direitos deste grupo social são aqueles que eles mesmos podem exercer a titularidade e, se assim o fizerem, darão novas perspectivas ao mundo.

Por isso, devemos ressignificar as atuações das crianças e dos adolescentes, mudando o entendimento dos adultos para com a infância, rompendo com a cultura da não-participação, criando mecanismos e espaços que auxiliem esse acesso e tomar medidas afirmativas para evitar o retrocesso na conquista dos direitos contidos na Convenção, permitindo que as crianças e os adolescentes se tornem protagonistas de seu próprio processo de vida e, consequentemente, sujeitos que aprendam a exercer a propriedade de seus direitos humanos, obtendo uma vida digna.

\section{REFERÊNCIAS}

BASTOS, Angélica Barroso. Direitos humanos das crianças e adolescentes: as contribuições do Estatuto da Criança e do Adolescente para a efetivação dos direitos humanos infanto-juvenis. Universidade Federal de Minas Gerais, 2012.

BOZZI, Sônia. La familia y otros grupos como garantes de los derechos de la niñez a 20 años de la convención de los derechos del niño. In: CONTRO, Mônica Gonzalez. Los derechos de niños, niñas e adolescentes: 20 años de la convención sobre los derechos del niño. México: Ed. Porrua, 2011.

FLORES, Joaquín Herrera. A reinvenção dos direitos humanos. Tradução de Carlos Roberto Diogo Garcia; Antônio Henrique Graciano Suxberger; Jefferson Aparecido Dias. Florianópolis: Fundação Boiteux, 2009. 
FUZIWARA, Aurea Satomi. Lutas Sociais e Direitos Humanos da criança e do adolescente: uma necessária articulação. p. 527-543. Serv. Soc. Soc.: São Paulo, 2013

GALICIA, Marco Antonio López. Una mirada a los derechos de las niñas y los niños: su resignificación. CNDH: México, 2016.

LIEBEL, Manfred. Sobre la historia de los Derechos de la infância. In: LIEBEL, Manfred; MUÑOZ, Marta Martínez (Coords.). Infancia y Derechos Humanos: Hacia una ciudadanía participante y protagónica. IFEJANT: Lima, 2009.

MALALA FUND. Malala's story. Disponível em: < https://www.malala.org/malalas-story > . Acesso em: 24 jul. 2018.

MARTUSCELLI, Patrícia Nabuco. O lugar das crianças nas relações internacionais: considerações sobre novos atores e a difusão de poder. p. 100-117. Revista de Estudos Internacionais: João Pessoa, 2013. v. 4.

OEA - Organização dos Estados Americanos. Convenção Americana sobre Direitos Humanos. 22 de novembro de 1969. Disponível em: <https://www.cidh.oas.org/basicos/portugues/c.convencao_americana.htm>. Acesso em: 23 jul. 2018.

ONU - Organização das Nações Unidas. Declaração Universal dos Direitos das Crianças. 20 de Novembro de 1959. Disponível em: < http://www.dhnet.org.br/direitos/sip/onu/c_a/lex41.htm >. Acesso em: 24 jul. 2018.

Convenção sobre os Direitos da Criança. 20 de novembro de 1989. Disponível em: < https://www.unicef.org/brazil/pt/resources_10120.html >. Acesso em: 24 jul. 2018.

RÚBIO, David Sanchez. Fazendo e desfazendo Direitos Humanos. EDUNISC: Santa Cruz do Sul, 2010.

VILLASEÑOR, Roxana Montejano; SAUCEDO, Martín Beltran; SILVA, Violeta Mendezcarlo. Un análisis transversal de los derechos humanos de las niñas y los niños ante la emergência.n. 18. REDHES: Sevilla, 2017.

WOLKMER, Antonio Carlos. História do direito no Brasil. $3^{\text {a }}$ ed. Forense: Rio de Janeiro, 2003.

Pluralismo jurídico: fundamentos de uma nova cultura no direito. 4. ed. rev. e atual. São Paulo: Saraiva, 2015.

YOUSAFZAI, Malala. Eu sou Malala: a história da garota que defendeu o direito à educação e foi baleada pelo Talibã. São Paulo: Companhia de Letras, 2013. 